\title{
Optimization of EDM Parameters for Al - TiC Composites Prepared through Powder Metallurgy Route
}

\author{
S. G. SHELVARAJ*, Sait A. NAVEEN** \\ *Chendhuran College of Engineering \& Technology, Pudukkottai, India, E-mail: sgshelva@yahoo.co.uk \\ **Chendhuran College of Engineering \& Technology, Pudukkottai, India, E-mail: naveensait@gmail.com \\ crossref http://dx.doi.org/10.5755/j01.mech.24.1.18951
}

\section{Introduction}

The conventional monolithic materials available in the market does not find its place for the critical applications like Automotive sector and Aerospace industry which requires the properties such as lighter weight with better wear resistance. Hence a new variety of material i.e. Metal Matrix Composite (MMC) is developed by employing various techniques like Stir casting, Powder Metallurgy etc., Each one has its merit over the other. It is very difficult to machine MMC due to the abrasive nature of the base metal Aluminum and the intermittent presence of reinforcements in the MMC. Moreover, the tool wear is high with the conventional tools [1-4].

Among the nonconventional machining process EDM is one of the effective processes of removing metal from harder surfaces. In the EDM process formation of mechanical stress at the machined surface is eliminated due to the absence of contact between the tool and the work material [5]. Prabu Basanna Choudri in his review and future scope article concluded that most of the EDM work has been carried out on Steel as the work material with copper rod in cylindrical shape as the most common tool material. Pulse on/off time, current are the more common influencing factor and focus on MRR, TWR, SR was given by many researchers [6].

Kathiresan [7] et al. has worked on EDM studies on aluminium alloy-silicon carbide composites developed by vortex technique and pressure die casting. The results reveal that material removal rate and surface finish are greatly affected by current and reinforcement percentage.

Kannan et al. reported [8] in their study that on machining of hard AMC with $5 \%$ TiC by using liquid casting technique, the processing parameters of EDM like discharge current, pulse on time and flushing pressure are optimized using Taguchi Techniques for minimum Tool wear rate(TWR).

Various optimization techniques such as Taguchi, DOE, ANNOVA, RSM are adopted to find the optimized parameter value while machining of different harder materials with EDM process. During analysis Metal Removal Rate and surface roughness value reveals that Pulse on Time, Current, Voltage has their impact on the response variables. The important parameters affecting the performance of the EDM process differ from one research to the other. Majority of the researchers proposed the impact of Peak current on the performance of EDM [9-14.]

All the above observations reveal that the parametric optimization of aluminum $\mathrm{TiC}$ composites prepared through powder metallurgy route needs much attention. Es- pecially evaluation of machining parameters for non-conventional machining process such as EDM has to be addressed in the present scenario in order to excel in the field of precision machining. Therefore, in this work, electric discharge machining of Aluminum (AP50) reinforced with various weight percentage of $\mathrm{TiC}$ particles prepared through powder metallurgy route have been studied and analyzed. The effect of parameters like Peak current, Pulse on time and Pulse off time on the machinability characteristics of $\mathrm{Al}$ with TiC MMC is evaluated. The same testing methodology is employed for testing the specimen with varying reinforcement percentage i.e., $2.5 \%, 5 \%$ and $7.5 \% \mathrm{TiC}$.

\section{Materials and experimentation}

\subsection{Materials}

In the present investigation Aluminium and $\mathrm{TiC}$ are used to form the MMC. All the elements are taken in their weight percentage. TiC with $44 \mu \mathrm{m}$ particle size and Aluminium (Grade AP50) of mesh size $72 \mu \mathrm{m}$ particle sizes with 3 proportions of TiC i.e., $2.5 \%, 5 \%, 7.5 \%$ by weight is used for the preparation of three varieties of MMC specimen.

\subsection{Fabrication of MMC}

Powder metallurgy technique is used for the fabrication of MMC in our study. The cylindrical shaped specimen of $25 \mathrm{~mm}$ diameter and $25 \mathrm{~mm}$ in length is fabricated for conducting the experiments. Aluminium powder and TiC powder of required proportion by weight are blended thoroughly and kept in Ball mill unit for 4 hours to obtain uniform mix. Then it is compacted to the required shape in the press by applying pressure and sintered in electric furnace by maintaining at a temperature of $425^{\circ} \mathrm{C}$.

\subsection{Mechanism of EDM}

In the EDM Process material is removed from the work piece by the spark formed between the electrode (Tool) and the work piece. Due to the formation of spark, heavy pressure is developed at the junction and higher temperature is prevailed. This leads to localized vaporization and melting.

\subsection{Machining of MMC}

Electronika4 axes CNC controlled EDM machine was used to carry out the experiments. Copper rod of diameter $12 \mathrm{~mm}$ was used as electrode. The machining parameters such as Electrode feed rate, dielectric fluid pressure and 
applied voltage were kept constant. Peak Current, Pulse on time and Pulse off time were considered as variable parameters in the present investigation. The EDM setup is shown in Fig. 1.

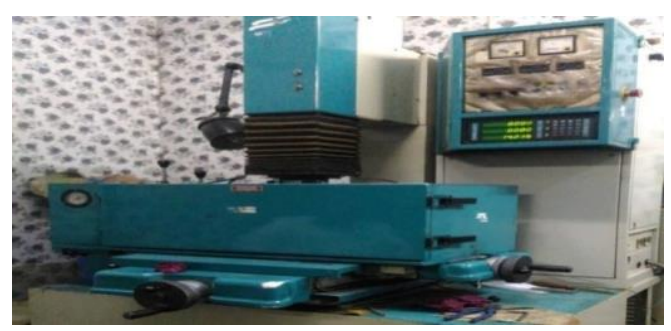

Fig. 1 Experimental set up of EDM process

The fabricated cylindrical MMC specimen is fixed in the fixture (Work holding device) which is mounted over the machine table and circular hole is drilled by feeding the electrode at a uniform rate. The time duration for machining each hole was recorded. The Metal Removal Rate can be determined.

$$
M R R=\frac{W 1-W 2}{T} \mathrm{~g} / \mathrm{min},
$$

where: $W 1(\mathrm{~g})$ is the initial weight of the specimen, $W 2(\mathrm{~g})$ is the final weight of the specimen after machining and $T$ is the machining time in min.

Machined MMC were collected and surface roughness is checked by using Mitutoyo make Surface Roughness tester and values were recorded.

SEM images of the machined surface were taken to study the nature of surface modification after machining. The process parameter values and levels are given in the Table 1.

Table 1

Process parameter values and its levels

\begin{tabular}{|c|c|c|c|c|c|}
\hline S. No & Parameters & \multicolumn{3}{|c|}{ Values } & Unit \\
\hline 1 & Pulse On Time & 40 & 60 & 80 & $\mu \mathrm{s}$ \\
\hline 2 & Pulse Off Time & 2 & 4 & 6 & $\mu \mathrm{s}$ \\
\hline 3 & Peak Current & 10 & 15 & 20 & A \\
\hline 4 & Dielectric Fluid & \multicolumn{3}{|c|}{ Kerosene } & \\
\hline 5 & Gap Voltage & \multicolumn{3}{|c|}{45} & $\mathrm{~V}$ \\
\hline 6 & Flush Rate & \multicolumn{3}{c|}{6} & $\mathrm{Kgf} / \mathrm{cm}^{2}$ \\
\hline
\end{tabular}

Experimental design for aluminium (AP 50) with TiC 2.5\%

\begin{tabular}{|c|c|c|c|c|c|}
\hline Ex. No & Pulse on time & Pulse off time & Peak current & M.R.R $(\mathrm{g} / \mathrm{min})$ & Roughness value $(\mu \mathrm{m})$ \\
\hline 1 & 40 & 2 & 10 & 0.06377709 & 11.334 \\
\hline 2 & 40 & 4 & 15 & 0.150980392 & 14.158 \\
\hline 3 & 40 & 6 & 20 & 0.168888889 & 15.0085 \\
\hline 4 & 60 & 2 & 15 & 0.155434783 & 14.2015 \\
\hline 5 & 60 & 4 & 20 & 0.182702703 & 15.064 \\
\hline 6 & 60 & 6 & 10 & 0.099044586 & 13.059 \\
\hline 7 & 80 & 2 & 20 & 0.198051948 & 16.2255 \\
\hline 8 & 80 & 4 & 10 & 0.13625 & 13.751 \\
\hline 9 & 80 & 6 & 15 & 0.16746988 & 14.3895 \\
\hline
\end{tabular}


Table 3

Experimental design for aluminium (AP 50) with TiC 5\%

\begin{tabular}{|c|c|c|c|c|c|}
\hline Ex. No & Pulse on time & Pulse off time & Peak current & M.R.R (g/min) & Roughness value $(\mu \mathrm{m})$ \\
\hline 1 & 40 & 2 & 10 & 0.047160169 & 12.2845 \\
\hline 2 & 40 & 4 & 15 & 0.10206525 & 15.239 \\
\hline 3 & 40 & 6 & 20 & 0.127163281 & 18.0505 \\
\hline 4 & 60 & 2 & 15 & 0.107641196 & 15.648 \\
\hline 5 & 60 & 4 & 20 & 0.138888889 & 18.2825 \\
\hline 6 & 60 & 6 & 10 & 0.049130435 & 13.5885 \\
\hline 7 & 80 & 2 & 20 & 0.142491468 & 18.9105 \\
\hline 8 & 80 & 4 & 10 & 0.050415094 & 14.815 \\
\hline 9 & 80 & 6 & 15 & 0.124487004 & 17.081 \\
\hline
\end{tabular}

Experimental design for aluminium (AP 50) with $\mathrm{TiC} 7.5 \%$

Table 4

\begin{tabular}{|c|c|c|c|c|c|}
\hline Ex. No & Pulse on time & Pulse off time & Peak current & M.R.R $(\mathrm{g} / \mathrm{min})$ & Roughness value $(\mu \mathrm{m})$ \\
\hline 1 & 40 & 2 & 10 & 0.085385439 & 12.869 \\
\hline 2 & 40 & 4 & 15 & 0.103244838 & 13.8 \\
\hline 3 & 40 & 6 & 20 & 0.171617162 & 14.9985 \\
\hline 4 & 60 & 2 & 15 & 0.13900135 & 14.3735 \\
\hline 5 & 60 & 4 & 20 & 0.180368098 & 15.215 \\
\hline 6 & 60 & 6 & 10 & 0.091234347 & 13.0995 \\
\hline 7 & 80 & 2 & 20 & 0.19047619 & 16.4825 \\
\hline 8 & 80 & 4 & 10 & 0.096721311 & 13.579 \\
\hline 9 & 80 & 6 & 15 & 0.153732809 & 14.433 \\
\hline
\end{tabular}

\section{Results and discussion}

From the production point of view to obtain better economy in an industry higher MRR is the most essential requirement. The next expectation from the customer is its aesthetic appearance and better life which necessitates the property fine Surface finish. First we are focussing our attention on the MRR. Minitab 16 Software is used to calculate the $\mathrm{S} / \mathrm{N}$ ratio and the mean of mean values for Design of Experiment with respect to MRR. By using the experimental data, values of the Response table of MRR for $2.5 \% \mathrm{TiC}, 5 \% \mathrm{TiC} \& 7.5 \% \mathrm{TiC}$ were calculated and presented in Table 5.

The amount of electrical energy available for metal removal is called Spark energy (discharge energy) (Em):

$$
\text { Em=Ton } x \operatorname{Vg} x I d
$$

From the above Eq. (2), it is very clear that the spark energy depends mainly on the factors Peak current, pulse on time and voltage applied. when the peak current increased, the number of anions striking the surface of the work piece gets increased. This in turn improves the concentration of higher spark energy and hence the temperature at the location of the spark is increased. This increased spark energy makes the temperature of the work piece to rise and melts more volume of the work piece that leads to higher metal removal rate.

This increased spark energy makes the temperature of the work piece to rise and melts more volume of the work piece that leads to higher metal removal rate.

The main effects plot shown in Figs. 3 (a, b, c) depicts the variation of $\mathrm{S} / \mathrm{N}$ ratio of MRR with process parameters i.e., pulse on, pulse off and peak current.

The $\mathrm{X}$ axis of the Plot indicates the value of each process parameters at their levels and the $\mathrm{Y}$ axis of the plot indicates the mean value of $\mathrm{S} / \mathrm{N}$ ratio of the response i.e., MRR.

Table 5

Response table of MRR for $2.5 \% \mathrm{TiC}, 5 \% \mathrm{TiC} \& 7.5 \% \mathrm{TiC}$

\begin{tabular}{|c|c|c|c|c|c|c|}
\hline \multicolumn{2}{|c|}{ Level } & 1 & 2 & 3 & Delta & Rank \\
\hline \multirow{2}{*}{$\sim$} & $\begin{array}{c}\text { Pulse on } \\
\text { time }\end{array}$ & -18.59 & -17.01 & -15.63 & 2.96 & 2 \\
\cline { 2 - 7 } & $\begin{array}{c}\text { Pulse off } \\
\text { time }\end{array}$ & -18.05 & -16.17 & -17.02 & 1.88 & 3 \\
\cline { 2 - 7 } & $\begin{array}{c}\text { Peak } \\
\text { current }\end{array}$ & -20.43 & -16.04 & -14.76 & 5.68 & 1 \\
\hline \multirow{2}{*}{$\approx$} & $\begin{array}{c}\text { Pulse on } \\
\text { time }\end{array}$ & -18.79 & -17.6 & -16.99 & 1.8 & 2 \\
\cline { 2 - 7 } & $\begin{array}{c}\text { Pulse off } \\
\text { time }\end{array}$ & -17.62 & -18.3 & -17.46 & 0.84 & 3 \\
\cline { 2 - 7 } & $\begin{array}{c}\text { Peak } \\
\text { current }\end{array}$ & -20.8 & -17.71 & -14.86 & 5.94 & 1 \\
\hline \multirow{2}{*}{$\approx$} & $\begin{array}{c}\text { Pulse on } \\
\text { time }\end{array}$ & -21.42 & -20.89 & -20.32 & 1.1 & 2 \\
\cline { 2 - 7 } & $\begin{array}{c}\text { Pulse off } \\
\text { time }\end{array}$ & -20.94 & -20.97 & -20.73 & 0.24 & 3 \\
\cline { 2 - 7 } & $\begin{array}{c}\text { Peak } \\
\text { current }\end{array}$ & -26.22 & -19.09 & -17.33 & 8.89 & 1 \\
\hline
\end{tabular}


From the Fig. 3 (a) it is evident that the MRR value is gradually increased with the increase in Peak Current up to certain limit. Then the MRR declines slightly. his is due to the fact that when the current applied is gradually increased, the number of the anions formed is also increased and hence the temperature responsible for melting the work piece is raised rapidly. After attaining a stage, if the current is increased further the anions formed have to penetrate further to melt the underlying material below the fused material. Hence a light decline is observed in the later stage. The same scenario is observed in Figs. 3 (b) and 3 (c) also. Figs. (3a, 3b, 3c) also displays that change in Pulse on Time has little impact on MRR. The plasma stream gets widened when the Pulse on Time is increased. The wider plasma increases the temperature of the work at a lower rate than that of by the Peak current. From the Figs. (3a, 3b, 3c), we infer that increase in the Pulse off time has no effect on MRR. This is because increase in Pulse off Time provides idler time between successive sparks.

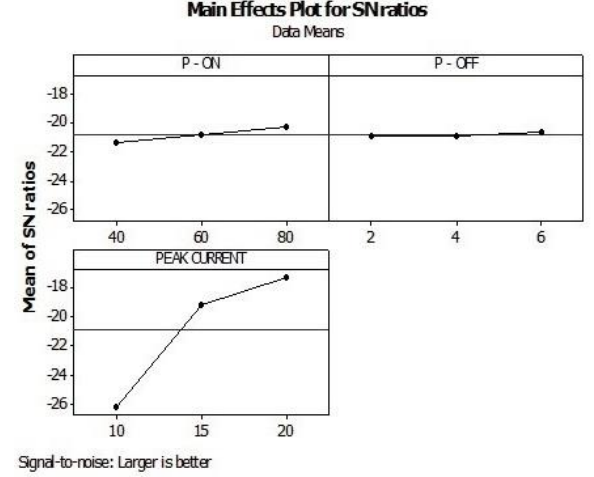

a

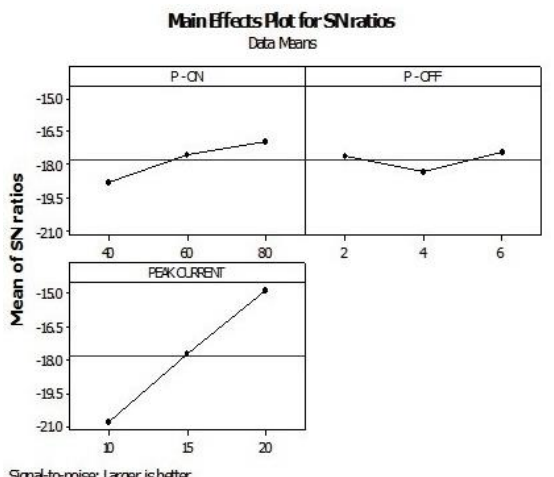

b

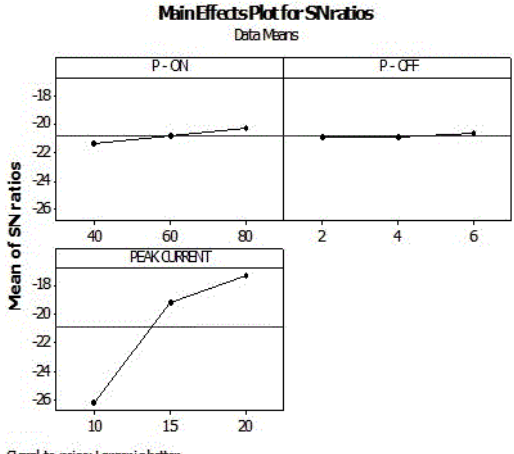

c

Fig. 3 Main effects plot : a - 2.5\% TiC; b-5\% TiC; c - 7.5\% TiC

\subsection{Analysis on material removal rate}

To find the significance of the parameters on response values F-test is the most reliable process. Higher $\mathrm{F}$ value for any parameter means more influence of that parameter on the response value.

From the Table 6, it is found that the most significant factor influencing the MRR is Peak current followed by Pulse on Time. Pulse off Time has lower impact on MRR
For the $2.5 \% \mathrm{TiC}$ variety the $\mathrm{F}$ Value for Peak current is 28.35 whereas for Pulse on Time the value is 6.01 and for Pulse off Time value is 1.23. This indicates that the Peak current is the dominating factor whose contribution is much higher than that of Pulse on Time. The same pattern is identified for the 5\% TiC and 7.5\% TiC varieties. During Analysis of variance, if the $P$ value for any process parameter is less than 0.05 , it is significant.

Table 6

Analysis of variance for material removal rate

\begin{tabular}{|c|c|c|c|c|c|c|}
\hline \multicolumn{7}{|c|}{ Aluminium (AP50) with TiC $2.5 \%$} \\
\hline Source & $\mathrm{DF}$ & Seq SS & Adj SS & Adj MS & $\mathrm{F}$ & $\mathrm{P}$ \\
\hline Pulse on time & 2 & 0.0023326 & 0.0023326 & 0.0011663 & 6.01 & 0.143 \\
\hline Pulse off time & 2 & 0.0004774 & 0.0004774 & 0.0002387 & 1.23 & 0.449 \\
\hline Peak current & 2 & 0.0110101 & 0.0110101 & 0.0055050 & 28.35 & 0.034 \\
\hline Residual error & 2 & 0.0003884 & 0.0003884 & 0.0001942 & & \\
\hline Total & 8 & 0.0142085 & & & & \\
\hline \multicolumn{7}{|c|}{ Aluminium (AP50) with TiC 5\% } \\
\hline Source & $\mathrm{DF}$ & Seq SS & Adj SS & Adj MS & $\mathrm{F}$ & $\mathrm{P}$ \\
\hline Pulse on time & 2 & 0.0010936 & 0.0010936 & 0.0005468 & 5.22 & 0.161 \\
\hline Pulse off time & 2 & 0.0002823 & 0.0002823 & 0.0001411 & 1.35 & 0.426 \\
\hline Peak current & 2 & 0.0120618 & 0.0120618 & 0.0060309 & 57.58 & 0.017 \\
\hline Residual error & 2 & 0.0002095 & 0.0002095 & 0.0001047 & & \\
\hline Total & 8 & 0.0136471 & & & & \\
\hline \multicolumn{7}{|c|}{ Aluminium (AP50) with TiC 7.5\% } \\
\hline Source & $\mathrm{DF}$ & Seq SS & Adj SS & Adj MS & $\mathrm{F}$ & $\mathrm{P}$ \\
\hline Pulse on time & 2 & 0.0002806 & 0.0002806 & 0.0001403 & 2.53 & 0.283 \\
\hline Pulse off time & 2 & 0.0000151 & 0.0000151 & 0.0000075 & 0.14 & 0.880 \\
\hline Peak current & 2 & 0.0121374 & 0.0121374 & 0.0060687 & 109.61 & 0.009 \\
\hline Residual error & 2 & 0.0001107 & 0.0001107 & 0.0000554 & & \\
\hline Total & 8 & 0.0125438 & & & & \\
\hline
\end{tabular}


With the above point of view also it is very clear that the Peak current is more significant parameter than Pulse on Time, whereas the Pulse of Time is not a significant Parameter.

By analysing the main effect plot and the mean response table for Metal removal rate the optimal combination of process parameters is presented in the Table 7. The optimum values are Peak current (level 3, value $20 \mathrm{~A}$ ), PON (level 3, value $80 \mu$ s), and POFF (level 1, value $2 \mu$ s).

From the contour graphs shown in Figs. 4 (a, b, c) variation of MRR with respect to the Peak current and Pulse on Time is displayed. Fig. 4 (a) shows that for a Pulse on Time up to a value of $60 \mu$ s with peak current value between $10 \mathrm{~A}$ to $11.5 \mathrm{~A}$ the MRR value is minimum. Maximum MRR is possible with Peak current value greater than $16 \mathrm{~A}$ with a Pulse on Time value greater than or equal to $55 \mu$ s. This is due to the fact that higher amount of Peak current and higher value of Pulse on Time enables generation of more spark energy to melt more material in lesser time.

Optimal combination of process parameters for MRR

Table 7

\begin{tabular}{|c|c|c|c|c|c|c|c|}
\hline \multirow{2}{*}{ S. No } & \multirow{2}{*}{ Parameter } & \multicolumn{2}{|c|}{$2.5 \% \mathrm{TiC}$} & \multicolumn{2}{c|}{$5 \% \mathrm{TiC}$} & \multicolumn{2}{c|}{$7.5 \% \mathrm{TiC}$} \\
\cline { 3 - 8 } & & Level & Value & Level & Value & Level & Value \\
\hline 1 & Pulse on time $(\mu \mathrm{s})$ & 3 & 80 & 3 & 80 & 3 & 80 \\
\hline 2 & Pulse off time $(\mu \mathrm{s})$ & 1 & 2 & 1 & 2 & 1 & 2 \\
\hline 3 & Peak current $(\mathrm{A})$ & 3 & 20 & 3 & 20 & 3 & 20 \\
\hline
\end{tabular}

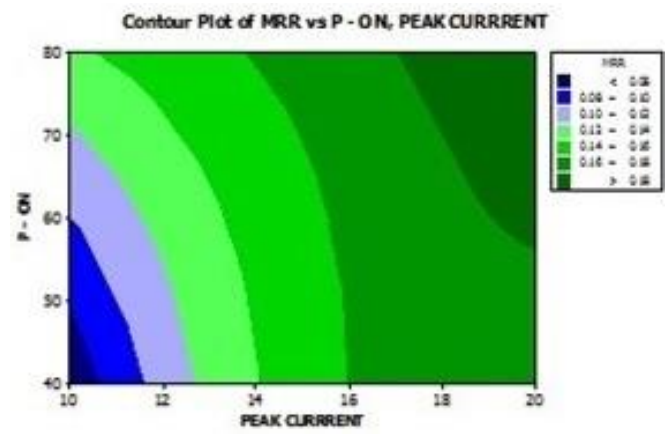

$\mathrm{a}$

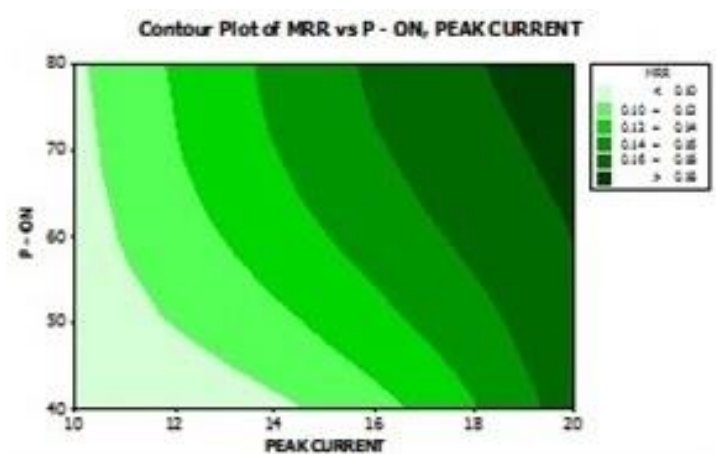

b

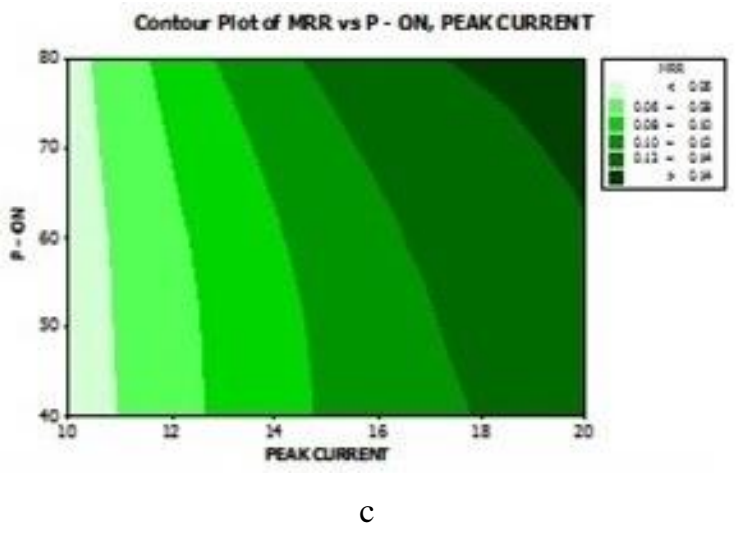

The same range of Peak current and Pulse on Time enables more MRR for the TiC 5\% and Tic 7.5\%. Maximum MRR value is obtained with optimum conditions for $2.5 \%$ Tic variety is 19.80 , for $5 \%$ Tic variety is 19.04 and for $7.5 \%$ Tic variety is 14.24 . This decline in MRR value is entirely due to the increase in percentage of $\mathrm{TiC}$ particles in the above three variety of composite materials. From this, we can infer that MRR is inversely proportional to the percentage of $\mathrm{TiC}$ presence, which is similar to the study carried out by Kathiresan et al [7].

The surface finish is the most expected requirement next to MRR. The surface finish value is lesser when the pit formation during the EDM process is smaller in size. The pit formation due to melting is controlled by lowering the temperature during spark. Minitab 16 Software is used to estimate the $\mathrm{S} / \mathrm{N}$ ratio and the mean of mean values for the design of Experiment with respect to surface roughness value Ra. From the experimental data, values for the response table of surface roughness value for the $2.5 \% \mathrm{TiC}$, $5 \% \mathrm{TiC} \& 7.5 \% \mathrm{TiC} \%$ were presented in Table 8.

The main effect for data means is shown in Figs. 5 $(a, b, c)$. Which depicts the changes in Ra value with process parameters i.e., Pulse on Time, Pulse off Time and Peak current.

The Figs. 5 (a, b, c) displays the effect of Pulse on time, Pulse off Time and Peak current. Surface roughness increases with the increase in Peak current. In the graph it is evident that if the current is increased up to 15 . The surface roughness value also increases steadily and if increased beyond that value the surface roughness value declines slightly. Hence to obtain lower value of surface roughness the Pulse on Time should be low. If Pulse on Time is increased the magnitude of $R a$ value increased is lower than that of the peak current.

From the Figs. 5 (a, b, c), we can infer that the increase in the Pulse off time has no effect on the $R a$ value. This is because increase in Pulse off Time reduces active impact of anions and hence little change in the $R a$ value.

Fig. 4 Contour plot on MRR: a - 2.5\% TiC; b - 5\% TiC; $\mathrm{c}-7.5 \% \mathrm{TiC}$ 
Response table of surface roughness for $2.5 \% \mathrm{TiC}, 5 \% \mathrm{TiC} \& 7.5 \% \mathrm{TiC}$

\begin{tabular}{|c|c|c|c|c|c|c|}
\hline \multicolumn{2}{|r|}{ Level } & 1 & 2 & 3 & Delta & Rank \\
\hline \multirow{2}{*}{ 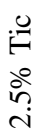 } & Pulse Off Time & -22.78 & -23.12 & -23 & 0.34 & 3 \\
\hline & Peak Current & -22.06 & -23.08 & -23.76 & 1.71 & 1 \\
\hline \multirow{2}{*}{$\begin{array}{l}0 \\
\dot{0} \\
\text { in }\end{array}$} & Pulse on Time & -22.60 & -22.99 & -22.16 & 0.79 & 2 \\
\hline & Peak Current & -23.39 & -23.02 & -23.84 & 1.67 & 1 \\
\hline \multirow{3}{*}{ 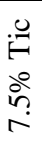 } & Pulse on Time & -23.53 & -23.93 & -24.53 & 1.01 & 2 \\
\hline & Pulse Off Time & -23.74 & -24.1 & -24.15 & 0.41 & 3 \\
\hline & Peak Current & -22.62 & -24.07 & -25.3 & 2.68 & 1 \\
\hline
\end{tabular}

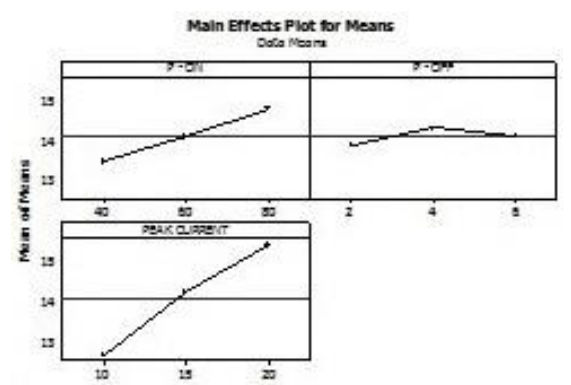

a

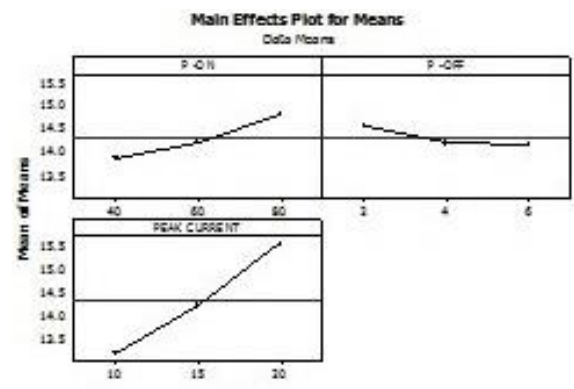

b

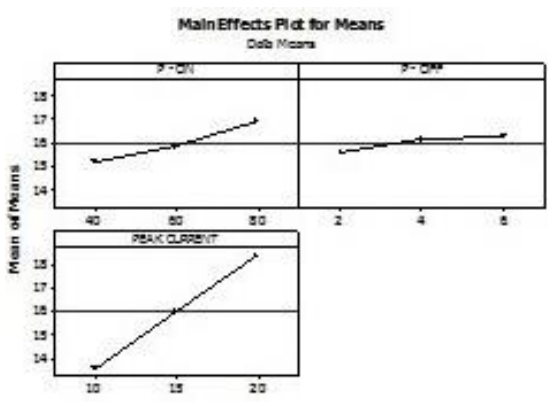

C

Fig. 5 Main effects plots of data means: a $-2.5 \% \mathrm{TiC}$; b - 5\% TiC; c $-7.5 \% \mathrm{TiC}$

3.2 Analysis on surface roughness

The significance of the parameters on response values $\mathrm{F}$ test is the ideal procedure. Analysis of variance of surface roughness for $2.5 \% \mathrm{TiC}, 5 \% \mathrm{TiC}$ and $7.5 \% \mathrm{TiC}$ are shown in Table 9. For the 5\% TiC variety the $\mathrm{F}$ Value for Peak current is 68.77 whereas for Pulse on Time the value is 10.95 and for Pulse off Time the value is 2.42 . This indicates that the Peak current is the more dominating factor whose contribution is more than that of Pulse on time.

Analysis of variance of surface roughness for $2.5 \% \mathrm{TiC}$

Table 9

\begin{tabular}{|c|c|c|c|c|c|c|}
\hline \multicolumn{7}{|c|}{ Aluminium (AP50) with TiC $2.5 \%$} \\
\hline Source & DF & Seq SS & Adj SS & Adj MS & $\mathrm{F}$ & $\mathrm{P}$ \\
\hline Pulse on time & 2 & 2.4930 & 2.4930 & 1.2465 & 1.87 & 0.349 \\
\hline Pulse off time & 2 & 0.2466 & 0.2466 & 0.1233 & 0.18 & 0.844 \\
\hline Peak current & 2 & 11.143 & 11.143 & 5.5716 & 8.35 & 0.107 \\
\hline Residual error & 2 & 1.3339 & 1.3339 & 0.6669 & & \\
\hline Total & 8 & 15.216 & & & & \\
\hline \multicolumn{7}{|c|}{ Aluminium (AP50) with TiC 5\% } \\
\hline Source & $\mathrm{DF}$ & Seq SS & Adj SS & Adj MS & $\mathrm{F}$ & $\mathrm{P}$ \\
\hline Pulse on time & 2 & 1.3660 & 1.3660 & 0.6830 & 10.95 & 0.084 \\
\hline Pulse off time & 2 & 0.3017 & 0.3017 & 0.1509 & 2.42 & 0.292 \\
\hline Peak current & 2 & 8.5755 & 8.5755 & 4.2877 & 68.77 & 0.014 \\
\hline Residual error & 2 & 0.1247 & 0.1247 & 0.0624 & & \\
\hline Total & 8 & 10.3680 & & & & \\
\hline \multicolumn{7}{|c|}{ Aluminium (AP50) with TiC 7.5\% } \\
\hline Source & DF & Seq SS & Adj SS & Adj MS & $\mathrm{F}$ & $\mathrm{P}$ \\
\hline Pulse on time & 2 & 4.6633 & 4.6633 & 2.3316 & 30.89 & 0.031 \\
\hline Pulse off time & 2 & 0.6557 & 0.6557 & 0.3278 & 4.34 & 0.187 \\
\hline Peak current & 2 & 35.310 & 35.310 & 17.655 & 233.93 & 0.004 \\
\hline Residual error & 2 & 0.1509 & 0.1509 & 0.0755 & & \\
\hline Total & 8 & 40.7799 & & & & \\
\hline
\end{tabular}


Table 10

Optimal combination of process parameters for surface roughness

\begin{tabular}{|c|c|c|c|c|c|c|c|}
\hline \multirow{2}{*}{ S1. No } & \multirow{2}{*}{ Parameter } & \multicolumn{2}{|c|}{$2.5 \% \mathrm{TiC}$} & \multicolumn{2}{|c|}{$5 \% \mathrm{TiC}$} & \multicolumn{3}{|c|}{$7.5 \% \mathrm{TiC}$} \\
\cline { 3 - 8 } & & Level & Value & Level & Value & Level & Value \\
\hline 1 & Pulse on time $(\mu \mathrm{s})$ & 1 & 40 & 1 & 40 & 1 & 40 \\
\hline 2 & Pulse off time $(\mu \mathrm{s})$ & 1 & 2 & 1 & 2 & 2 & 4 \\
\hline 3 & Peak current $(\mathrm{A})$ & 1 & 10 & 1 & 10 & 1 & 10 \\
\hline
\end{tabular}

The same pattern is identified for the $7.5 \% \mathrm{TiC}$ and $2.5 \% \mathrm{TiC}$ varieties. Also the pulse of time is not a significant parameter. The optimal combination of process parameters for surface roughness is presented in the Table 10. The optimum values are PON (level 1, value $40 \mu \mathrm{s}$ ), Peak current (level 1, value $10 \mathrm{~A}$ ) and POFF (level 1, value $2 \mu$ s) to attain fine surface finish.

Fig. 10 (a) shows that the $R a$ value is minimum for Pulse on Time value lesser than $45 \mu$ s with peak current value between $10 \mathrm{~A}$ to $11 \mathrm{~A}$. The same range of Pulse on
Time and Peak current exhibits the same pattern of results for the TiC 5\% and Tic 7.5\%. Minimum $R a$ value obtained with optimum values of the process parameter for $2.5 \%$ of $\mathrm{TiC}$ variety is 11.33 microns, for $5 \%$ of TiC variety is 12.28 microns, and for $7.5 \%$ of TiC variety is 12.87 microns. The value of surface roughness increases with the increase in the percentage content of TiC particles. Hence it is inferred that increase in percentage of $\mathrm{TiC}$ particles leads to higher $R a$ value.

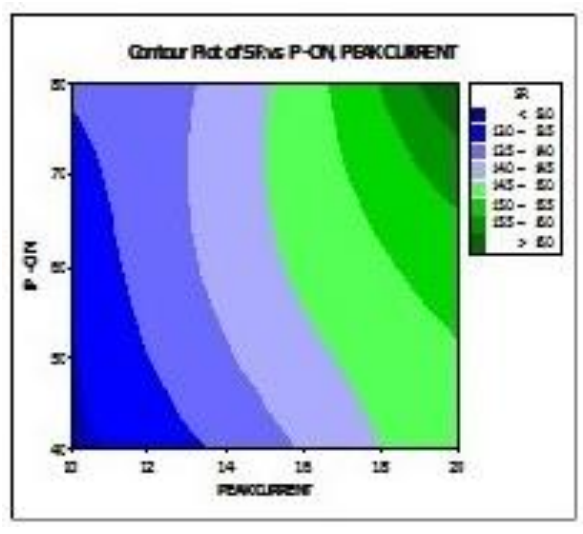

a

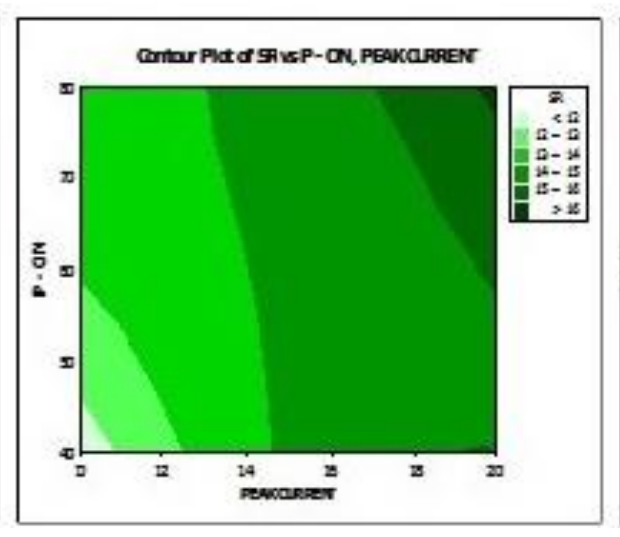

$\mathrm{b}$

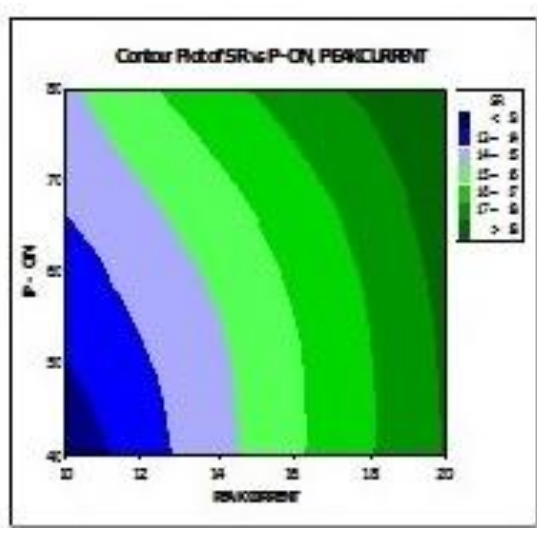

c

Fig. 6 Contour plot on SR: a - 2.5\% TiC; b-5\% TiC; c - 7.5\% TiC

\subsection{Microstructure analysis}

SEM images of machined surface were taken to study the surface and it is shown in Figs. $7(a, b, c)$. It is observed from the images that; pit formation takes place at machined surface due to spark. It is also evident from the images that the machined surfaces have no other damages such as surface crack. The reinforcement particles are uniformly distributed in the matrix material which enhances the mechanical properties of the prepared composites.

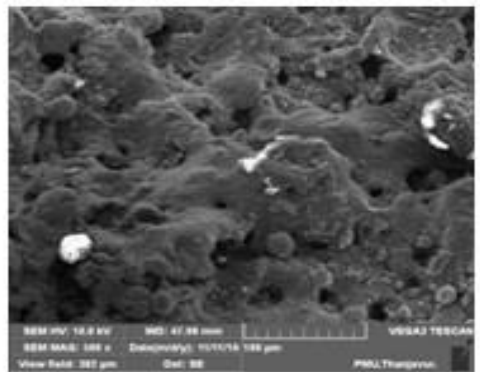

a

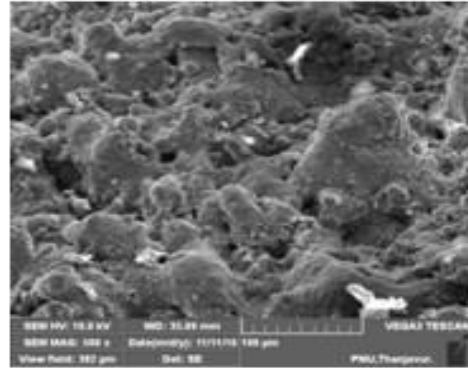

b

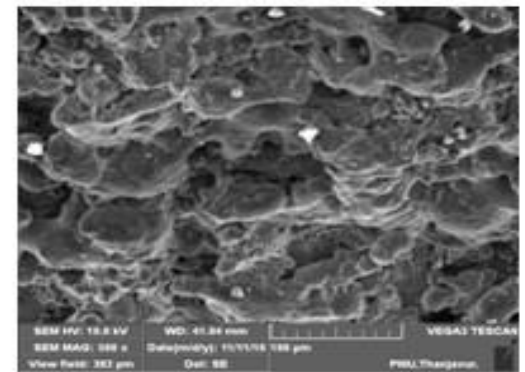

c

Fig. 7 Micro structure: $\mathrm{a}-$ Aluminium+2.5\% TiC; $\mathrm{b}-$ Aluminium+ $5 \% \mathrm{TiC}$; $\mathrm{c}-$ Aluminium $+7.5 \% \mathrm{TiC}$

\section{Conclusions}

From the analysis after the completion of the experiments, it is concluded that:

1. Increase in Peak current and increase in Pulse on time improves the metal removal rate whereas the increase in the value of Pulse off time has no significant effect.
2. The increase in the percentage of $\mathrm{TiC}$ decreases the metal removal rate. This is due to the fact that the harder TiC particles present in the specimen retards the process. Thus the metal removal rate is decreased with increase in the reinforcement material i.e., TiC

3. To obtain higher material removal rate, more peak current and more pulse on time should be ensured. 
4. Better Surface finish is obtained with lower Pulse on time and lower peak current. This is due to the formation of minimum pits and lesser amount of heat generation at the spark and sufficient time to flush the debris and cools the melted area.

5. The percentage of $\mathrm{TiC}$ present is responsible for the formation of pits around $\mathrm{TiC}$ particles. i.e., more TiC percentage leads to more pits and hence poor surface finish (Higher $R a$ value) is obtained.

\section{References}

1. Christy, T.V.; Murugan, N.; Kumar S. 2010. A Comparative Study on The Microstructures and Mechanical Properties of Al 6061 Alloy and The MMC Al 6061/Tib2/12P. Journal of Minerals \& Materials Characterization \& Engineering, 9 (1): 57-65. https://doi.org/10.4236/jmmce.2010.91005.

2. Shivam, P.; Chaudhary; Piyush Kumar Singh; Shubham Rai; Hiren Patel; Bharat Kumar. 2015. A Review on Effect of Reinforcement Particles on the Mechanical Properties of Aluminium Based Composites, International Journal of Innovative Research in Science, Engineering and Technology, 4 (9): 8377-8382. http://dx.doi.org/10.15680/IJIRSET.2015.0409080.

3. Jerome, S.; Ravisankar, B.; Pranab Kumar Mahato; Natarajan, S. 2010. Synthesis and evaluation of mechanical and high temperature tribological properties of in-situ $\mathrm{Al}-\mathrm{TiC}$ composites, Tribology International 43: 2029-2036.

https://doi.org/10.1016/j.triboint.2010.05.007.

4. Manickam Ravichandran; Abdullah NaveenSait; Veeramani Anandakrishnan. 2014. Workability studies on $\mathrm{Al}+2.5 \% \mathrm{TiO}_{2}+\mathrm{Gr}$ powder metallurgy composites during cold upsetting. Materials Research, 17(6): 14891496. http://dx.doi.org/10.1590/1516 - 439.258713.

5. Jawalkara, A. K.; Sharmab; and Pradeep Kumar. Electric Discharge Machining: Variants, Hybridization and Research Potentials, International Journal of Production and Quality Engineering, 2(1): 27-41. http://dx.doi.org/10.1177/0954405413508939.

6. Prabhu Basanna choudri; Gorabal, S.V. 2016. Experimental Investigations in to the Effect of Process Parameters on Performance Measures of Sink EDM Process A Review till the year 2010 and Future Work, International Journal of latest trends in Engineering and technology, 6: 504-511.

7. Kathiresan, M.; Sornakumar. T. 2010. EDM studies on Aluminium Alloy-Silicon Carbide composites developed by Vortex Technique and Pressure Die casting, Journal of Minerals \& Materials Characterization \& Engineering, 9(1):79-88. http://dx.doi.org/10.4236/jmmce.2010.91007.

8. Kannan, S.; Ramanthan, K. 2014. Optimization of EDM Parameter of Al/TiC Composite Using Taguchi Methodology, Middle-East Journal of Scientific Research, 22(1):121-127.

http://dx.doi.org/10.5829/idosi.mejsr.2014.22.01.21832

9. Harmanpreet; Manpreet Singh; Bipendeep. 2015. Optimization of Edm Process Parameters Using Taguchi Method a Review, International Journal of Research in Engineering and Technology 04: 625-634. https://doi.org/10.15623/ijret.2015.0404003,9-1.

10. Varinder Khurana; Harsimran singh sodhi; Amarjeet Singh Sandhu. 2014. The Effect of Die Sinking Process Parameters on Surface roughness of D2 Steel Using Taguchi's Method, International Journal of Innovative Research in Engineering \& Multidisciplinary Physical Sciences, 2: 62-72.

11. Rajendran, S.; Marimuthu, K. 2012. Experimental investigation of electrode wear and rapidly re-solidified layer thickness in T90Mn2W50Cr45, MECHANIKA. 18(6): 691-697.

12. Abinesh, P.; Varatharajan, K.; Satheesh Kumar, G. 2014. Optimization of Process Parameters Influencing MRR, Surface Roughness and Electrode Wear During Machining of Titanium Alloys by WEDM, International Journal of Engineering Research and General Science 2(4): 719-729.

13. Panneer Selvam, M.; Ravikumar, R.; Ranjith Kumar, P.; Deepak, and U. Experimental investigation of Machining Parameters in Electrical Discharge Machining using En36 Material, ARPN Journal of Engineering and Applied Sciences, 11: 1245-1251.

14. Kamaljit Singh Mahal; Navjot Singh Mahal; Kamaldeep Chugh. 2014. Experimental Investigation of Surface Roughness by the Application of Taguchi Method in Electric Discharge Machining, International Journal of Research in Mechanical Engineering \& Technology, 4: 53-55.

\section{S. G. Shelvaraj, Sait A. Naveen}

\section{OPTIMIZATION OF EDM PARAMETERS FOR AL - TIC COMPOSITES PREPARED THROUGH POWDER METALLURGY ROUTE}

S u m m a r y

This work focuses on the behavior of Aluminum (AP50) reinforced with Titanium Carbide Metal Matrix Composite (MMC) during machining in Electrical Discharge Machining (EDM) process. Not many attempts were made to establish EDM machining characteristics of MMCs prepared through powder metallurgy route. Hence the nonconventional machining technique EDM is the best alternate to machine intricate shape in MMC. The material used in this study is Aluminum (AP 50) with 3 proportions of TiC (i.e., $2.5 \%, 5 \%$ and $7.5 \%$ ). The machining is performed by varying the Pulse On time, Pulse Off time and Peak Current while other parameters such as Dielectric flushing pressure, Electrode feed rate and Applied voltage are kept unchanged. The parameter optimization is smaller $(2.5 \%)$ performed using Taguchi techniques. It is found that increase in Metal removal rate and reduction in surface roughness is achieved with the TiC reinforcement. It is also found that the metal removal rates as well as surface roughness are more influenced by the parameters Peak Current and Pulse on Time.

Keywords: MMC, Electrical Discharge Machining (EDM), Pulse on Time, Pulse off Time, Taguchi techniques.

Received September 04, 2017 Accepted February 15, 2018 